\title{
CUSTO DO CRÉDITO BRASILEIRO NO PERÍODO DE PANDEMIA ${ }^{1}$
}

\author{
Cayan Atreio Portela Bárcena Saavedra²
}

\section{SINOPSE}

O quadro atípico ocasionado pela pandemia do novo coronavírus provocou mudanças abruptas no cenário econômico. Visando mitigar tal efeito catastrófico, políticas de flexibilização monetária e incentivo ao crédito foram adotadas, alterando o comportamento de alguns indicadores econômicos em relaçáo ao que se esperaria caso nenhuma medida fosse tomada. Diante de tal conjuntura, o custo do crédito foi afetado, apresentando um declínio acentuado, em grande parte devido à queda do custo de crédito e à inadimplência. Neste artigo, diversos recortes do Indicador do Custo de Crédito (ICC) e o spread do ICC (dado pela diferença entre o ICC e o custo de captaçáo) são analisados, contrastando o comportamento das séries em diferentes composiçôes. Os dados examinados são provenientes do Sistema Gerenciador de Séries (SGS), do Banco Central do Brasil (BCB), que disponibiliza dados entre janeiro de 2013 e abril de 2021.

Palavras-chave: retrospectiva; pandemia; economia brasileira; indicadores de crédito.

O custo do crédito no Brasil é mensurado pelo Indicador de Custo de Crédito (ICC), divulgado desde abril de 2017 pelo Banco Central do Brasil (BCB). O indicador mensura o custo médio, pela ótica do tomador, de todas as operaçóes de crédito. Para a estimativa em um dado período, são consideradas todas as operaçóes de crédito vigentes no sistema financeiro, independentemente da data de contrataçáo. Desta maneira, o cálculo leva em conta os contratos recentes e os mais antigos, e todos aqueles que ainda estáo em vigência (BCB, 2020).

O Relatório de Economia Bancária 2020, disponibilizado pelo BCB, apresenta a decomposição do ICC visando mensurar os principais fatores que compóem o custo do crédito para o tomador (BCB, 2021). O indicador é decomposto em cinco componentes, a seguir descritos.

1) Custo de captação: despesas das instituiçôes financeiras ( $I F s)$ com o pagamento de juros nas captaçôes de recursos.

2) Inadimplência: perdas decorrentes do não pagamento de dívidas, juros não recebidos de operaçôes com atraso e descontos concedidos.

3) Despesas administrativas: despesas diversas, necessárias para realizar operaçóes de crédito.

4) Tributos e Fundo Garantidor de Crédito (FGC): tributos sobre operaçóes de crédito pagos pelos clientes e pelas instituiçôes e contribuiçôes mensais, por parte das instituiçôes, para o FGC.

5) Margem financeira do ICC: a parte do ICC que remunera o capital dos acionistas das IFs pelo crédito, e outros fatores incluindo erros e omissóes nas estimativas.

Os componentes possuem diferentes pesos em relaçáo ao valor final do ICC e do seu spread (obtido ao se excluir a parcela correspondente ao custo de captaçáo). Entre 2018 e 2020, o ICC médio ajustado foi de 18,47 pontos percentuais (p.p.). No mesmo período, observou-se na composiçáo do indicador os seguintes valores médios para cada componente: custo de captação (6,11 p.p.), inadimplência (3,94 p.p.), despesas administrativas (3,65 p.p), tributos e FGC (2,42 p.p.) e margem financeira (2,34 p.p.). Assim, nota-se que o custo de captação 
representou o maior custo para o ICC, seguido da inadimplência, das despesas administrativas, dos tributos e do FGC e, por fim, da margem financeira. O ordenamento se altera apenas em 2019, quando a margem financeira apresentou valor maior que os tributos e o FGC, de 2,62 p.p. contra 2,43 p.p.

O spread do ICC, por sua vez, é dado pela diferença entre o ICC e o custo de captação. Considerando o valor médio mencionado anteriormente de 18,47 p.p. (ICC) e 6,11 p.p. (custo de captaçáo), o spread do ICC apresentou média de 12,35 p.p. Dessa maneira, a inadimplência correspondeu à maior fatia da decomposiçáo do spread.

Utilizando dados provenientes do Sistema Gerensiador de Séries (SGS) do BCB, é possível observar o comportamento de ambos os indicadores (ICC e spread) em diferentes recortes. O gráfico 1 traz as respectivas séries, segregadas por pessoa física (PF) e jurídica (PJ) e por tipo de recurso (livre ou direcionado).

\section{GRÁFICO 1}

Séries dos indicadores, por pessoa física e jurídica e por tipo de recurso (jan. 2013-abr. 2021)

(Em \%)

$1 \mathrm{~A}-\mathrm{ICC}$

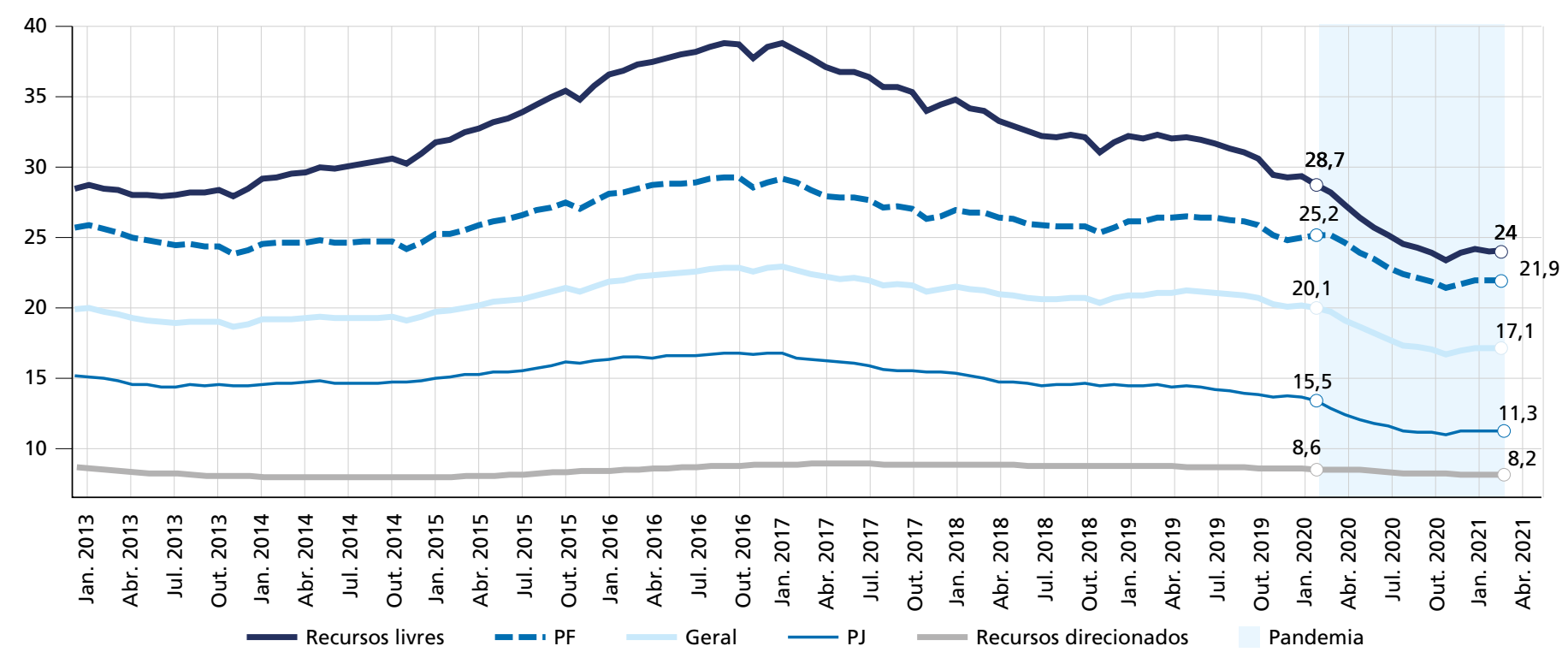

1B - Spread do ICC

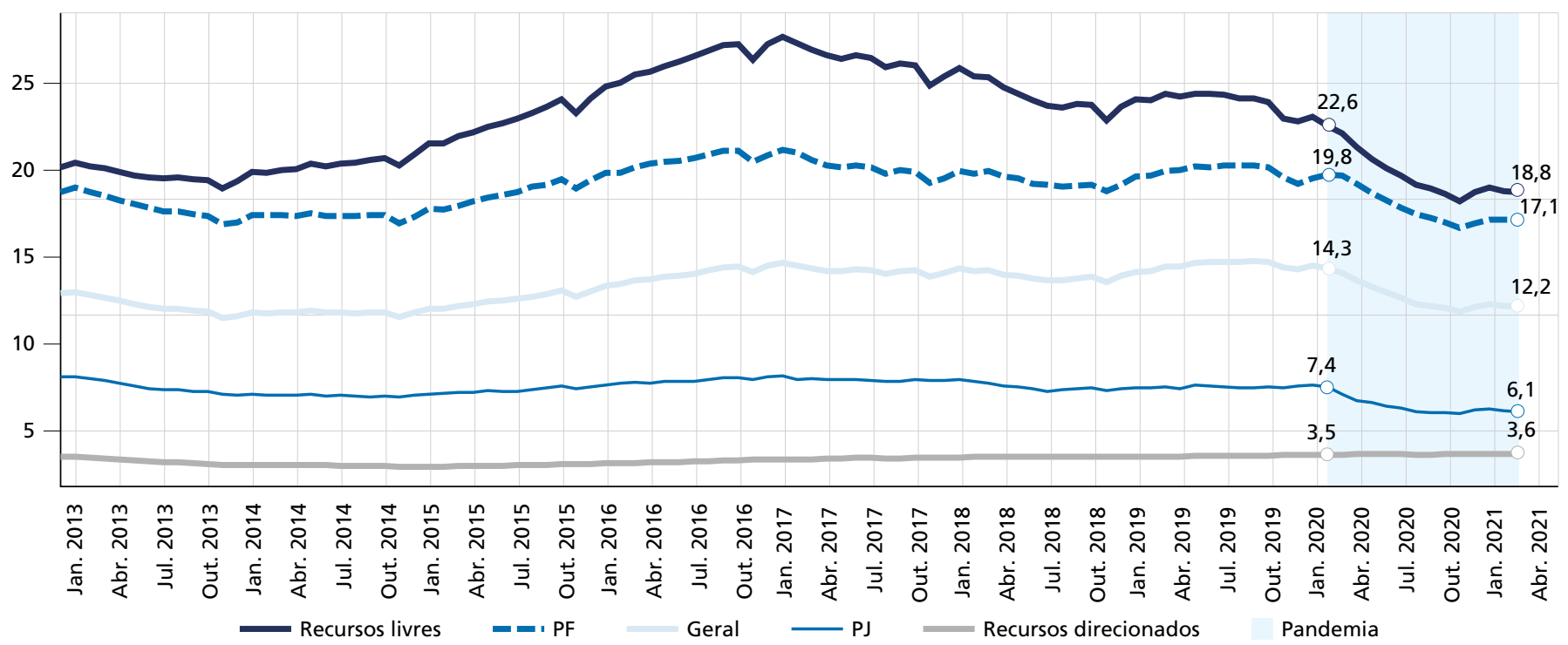


O comportamento das curvas ilustra algo esperado: um comportamento mais volátil em recursos livres e em PFs (que em grande parte realizam operaçóes com recursos livres) e mais estável em recursos direcionados e em PJs (que, por sua vez, são maioria em operações em recursos direcionados). Desta forma, a característica média dos indicadores (tanto ICC, quanto spread do ICC) é influenciada, por um lado, pelo alto volume das operaçóes em recursos livres, e, por outro lado, pela estabilidade provinda de operaçóes direcionadas. Naturalmente, observa-se um comportamento correlato entre as séries do ICC e seu spread.

No período pós-pandemia, a trajetória do ICC foi de queda: saiu do patamar de 20,06 p.p. em março de 2020 e atingiu o mínimo da série em dezembro de 2020 com 16,76 p.p. (no mesmo mês em 2019 o valor foi de 20,27 p.p.). Em 2021, o ICC vem apresentando uma leve subida, chegando a 17,19 p.p. em abril. O spread do ICC segue de maneira similar: em março de 2020 seu valor foi 14,35 p.p., atingindo a mínima de 11,81 p.p. em dezembro de 2020 e chegando a 12,15 p.p. em abril de 2021. Medidas de apoio tomadas por parte do governo, objetivando mitigar os efeitos da pandemia no cenário econômico, podem ser consideradas como fatores exógenos que influenciaram o comportamento de queda. Contínuas reduçôes na taxa Selic, por exemplo, reduzindo o custo de captaçáo, e a flexibilização de prazos em operaçóes de crédito, com subsequente redução da inadimplência, podem ter sido fatores importantes.

Para recursos livres, é natural que os indicadores apontem para uma maior remuneração do ponto de vista de instituições financeiras, uma vez que para proporcionar o produto de crédito é apropriado que a rentabilidade das carteiras de crédito livre apresente valor superior ao que seria em uma situaçáo hipotética de ausência de crédito direcionado (BCB, 2018). Dessa maneira, para recursos livres, os indicadores apresentam maiores valores. O ICC caiu de 28,7 p.p. em março de 2020 para 23,36 p.p. em dezembro de 2020, nível mínimo no período pós-pandemia. Em abril, o índice atingiu o valor de 24,14 p.p.

O spread do ICC em recursos livres, considerando a mesma janela temporal, foi de 22,59 p.p. em março de 2020, com mínima de 18,23 p.p. em dezembro de 2020, chegando em 18,79 p.p. em abril de 2021. Tanto para o ICC quanto para o spread, a máxima no período ocorreu em fevereiro de 2021, com o 24,21 p.p. e 19,04 p.p., respectivamente. Nesta configuração de recursos livres, os maiores níveis observados para o custo do crédito foram para PFs, com 40,56 p.p. em março de 2020, declinando até 33,53 p.p. em dezembro de 2020 e chegando a 34,8 p.p. em abril de 2021. O mesmo ocorreu para o spread do ICC em recursos livres, no qual os maiores níveis se concentraram no recorte para PFs.

Para o custo de crédito em recursos direcionados, os maiores valores do ICC no período foram observados para financiamento imobiliário (PJ) com 10,94 p.p. em março de 2020, com leve queda para 10,36 p.p. em abril de 2021. O ICC para crédito rural (PJ) apresenta valores mais baixos: 7,72 p.p. em março de 2020 e 6,08 p.p. em abril de 2021. Nos recursos direcionados, o spread do ICC foi maior para PFs (4,02 p.p.) do que para PJs (2,83 p.p. em abril de 2021).

Programas de incentivo ao crédito, como o Programa Nacional de Apoio às Microempresas e Empresas de Pequeno Porte (Pronampe), o Programa Emergencial de Acesso a Crédito (Peac) e o Programa Emergencial de Suporte a Empregos (Pese), os quais foram concebidos para prover crédito e atenuar a crise econômica decorrente da pandemia da Covid-19, são refletidos nas séries de PJs. Nesse caso, nota-se uma leve subida a partir de dezembro de 2020, talvez ocorrida diante de um leve relaxamento em medidas de restrição em relação à pandemia, mas que foi cessado com o receio de uma segunda onda do vírus.

A queda da taxa básica de juros, que já vinha acontecendo desde 2018, foi ainda mais acentuada com a intensificação da pandemia da Covid-19, ocasionando uma queda no custo de captação, que foi o principal componente para o declínio do ICC (BCB, 2021).

Os comportamentos das cinco componentes descritas anteriormente, que impactam diretamente os dois indicadores analisados, podem ter sido guiados em consequência das medidas tomadas pelo governo em relação à programas de crédito, como queda na inadimplência e nas taxas de juros, visando mitigar efeitos negativos da 
pandemia. Todavia, esses comportamentos devem ser analisados com cautela, dado que fenômenos não observados (por conta das açóes mencionadas) podem vir a se manifestar em um futuro próximo.

\section{REFERÊNCIAS}

BCB - BANCO CENTRAL DO BRASIL. Relatório de economia bancária 2017. Brasília: BCB, jun. 2018. Disponível em: $<$ https://bit.ly/3r5BeRn>.

Relatório de economia bancária 2019. Brasília: BCB, jun. 2020. Disponível em: <https://bit.ly/3B0sDUj>. Relatório de economia bancária 2020. Brasília: BCB, jun. 2021. Disponível em: <https://bit.ly/3wCkF0y>. 